\title{
Irrigated agriculture: Water resources management for a sustainable environment
}

In the last decade, research on irrigation has mainly been aimed at reducing crop water consumption. In arid and semiarid environments, in relation to the limited water resources, the use of low quality water in agriculture has also been investigated in order to detect their effects on soil physical properties and on crop production. More recently, even the reduction of energy consumption in agriculture, as well as the effects of external factors, climate change and agricultural policies, have been major research interests.

All these objectives have been considered in the papers included in this special issue. However, in the last years, approaches aimed at reducing crop water requirements have significantly changed. Remote sensing with satellites or unmanned vehicles, and vegetation spectral measurements, among others, represent in fact the newest frontier of existing technologies. Knowledge of soil hydraulic properties, often forgotten because of the difficulty of their estimation, can also be considered as a new way to reduce water consumption

The so-called modernisation of irrigation systems, mainly directed to shift surface irrigation to pressurised irrigation, has meant a significant increase in energy demand. The energy cost has so far not been considered in the cost of farmers, so exploring new energy sources, especially renewable ones like wind, has become a major goal for researchers in irrigation.

Alternative water sources are necessary given the scarcity of conventional resources, but their influence on the soil and the crop itself should be considered before they can be adopted and generalised.

As if that were not enough, some external factors such as the threat of climate change or ups and downs of agricultural policies, in particular European agricultural policy, significantly affect the water needs of crops, sometimes with opposite effects on water consumption, that seems to increase in the first case and to reduce in the second.

The purpose of this special issue is to report in more detail research presented at the SSS10.2 session of European Geoscience Union (EGU) assembly, held in Vienna in April 2013. The selected contributions, summarised below, represent some examples of water resources management in the frame of sustainable development.
Levy et al. (2014) consider the importance of using treated wastewaters for irrigation in arid and semi-arid countries and evidence the possible changes in soil structure and stability as well as in their hydraulic properties due to water salinity and sodicity. They investigated the relationships between the sodium absorption ratio (SAR) of irrigation water and of the soil solution and the percentage of exchangeable sodium (ESP) measured in orchards irrigated, for a long time, with treated wastewaters. The study clearly indicated accumulation of exchangeable sodium in the soil as well as ESP levels higher than 8, under long term irrigation with treated wastewater (SAR 3-5). According to these results, the hypotheses of absence of chemical equilibrium between the SAR of irrigation water, the SAR in the soil solution and then the ESP due to the alternating cycles of rainfall and irrigation provide better explanations of the sodification observed in the soil profile.

The importance of using organic wastes in irrigated areas vulnerable to nitrate pollution has been investigated by Requejo Mariscal et al. (2014). Based on the results of two years of field experiments carried out on melon crop planted in a shallow sandy loam soil of central spain and by using different rates of wine-distillery waste compost, applied with two different irrigation regimes, it was possible to quantify the groundwater pollution risk according to some environmental indices. The research evidenced how, in the treatments with compost addition, applying excess irrigation during the crop cycle leads to an increase in nitrate leaching, whereas when using an adjusted irrigation strategy aimed to satisfy the actual plant needs, the addition of compost reduces leaching without affecting crop yield. This latter irrigation strategy, therefore, should be recommended as avoiding the risk of groundwater contamination.

A simple method for economic evaluation of water pumping technologies applied to irrigated greenhouse crops, i.e. wind pump, solar photovoltaic pumping, diesel generator and connection to the electrical grid, under the different socio-economic conditions existing in Cuba, Spain and Pakistan, has been suggested by Díaz et al. (2014). In particular, the proposed methodology allows comparison of different technologies in terms of levelised energy costs by considering, in the different countries, the critical factors affecting the decision process, like wind resource availability, 
distance to electrical grid, required volume of water storage and planting dates. The analysis evidenced that for each country examined, if a grid connection exists near the pumping plant, using wind pumps is economically not optimal, while, in the other cases, it is necessary to consider the distance from the electrical grid and the available wind resource.

Gumiere et al. (2014) consider the spatial variability of soils and propose combining measurements of soil properties and fruit yield to manage irrigation of cranberry. Initially, the best interpolation method to map the spatial variability of soil matric potential, water table depth and yield was investigated, based on experiments carried out in 2012, in two cranberry fields in Quebec city, Canada. Then, using the optimal interpolation method to generate maps of each considered variable, applications of Hydrus 1D model allowed some interesting considerations related to irrigation management. They observed that the spatial variability of cranberry yield was strongly affected by soil hydraulic properties, suggesting that the total irrigation amounts can be reduced by up to four times when information on spatial variability of soil hydraulic properties is considered. Rallo and Provenzano (2013), Rallo, Baiamonte, Manzano Juárez, and Provenzano (2014), using agro-hydrological models, have also recently emphasised the importance of considering the spatial variability of soil hydraulic properties to estimate root water uptake.

The importance of using emitters able to avoid soil particle and root intrusion in subsurface drip irrigation (SDI) systems has been emphasised by De Jesus Souza, Rodrigues Sinobas, Sánchez, Arriel Botrel, and Duarte Coelho (2014). A new prototype emitter, appropriate for SDI systems, was therefore designed, manufactured and tested under laboratory and field conditions. The proposed design combines the effects of a hydraulic mechanism regulated by the operating pressure head through the deformation of an elastic membrane. The developed prototype prevented emitter clogging due to roots and soil particles in experimental evaluations, though further studies are necessary to consider the physical features of the membrane, as well as to develop an element to regulate emitter flow rate, so as to improve water distribution uniformity in the field.

Rallo, Minacapilli, Ciraolo, and Provenzano (2014), using field spectroscopy at leaf and tree canopy level in an olive grove of Sicily, Italy, assessed two different approaches to detect crop water status, i.e. optimisation of specific Vegetation Indices (VIs), and Partial Least Squares Regression (PLSR). Based on an experimental data-set acquired in 2011, the proposed approaches provided a non-destructive and fast evaluation of leaf water potential, especially when using spectral data acquired in the near and shortwave infrared regions (NIR-SWIR).

Making reliable estimates of daily evapotranspiration (ET) fluxes in relatively large areas is a key challenge when facing the continuing reduction in available water (Cammalleri, Ciraolo, Minacapilli, \& Rallo, 2013). Considering the growing availability of data collected by low-cost sensors installed on satellites and/or in unmanned aerial vehicles, remote sensing technology represents great promise (Jha \& Chowdary, 2006) for use in monitoring and managing irrigation over long periods (Santos, Lorite, Tasumi, Allen, \& Fereres, 2010).
Following this research line, the study of Pôças et al. (2014) proposes a methodology to parameterise, for different growth stages of a super-intensive olive orchard (discontinuous woody crop) in Southern Portugal, a satellite-based surface energy balance model, METRIC, aimed at estimating and mapping crop evapotranspiration (ET). In order to improve ET estimations at different growth stages by using remote sensing, they propose a three-source condition, so as to differentiate the radiometric surface temperature into three terms, i.e. the temperature of the canopy, of the shaded ground surface and of the sunlit ground surface. They then compute the momentum roughness length using the Perrier equation and adopt new equations to estimate Leaf Area Index (LAI) from a Soil Adjusted Vegetation Index (SAVI). They find that the METRIC algorithm allowed better understanding of the spatial variability of ET within the olive orchard, which can aid irrigation management, particularly when used in conjunction with a simulation model for irrigation scheduling. However, further research will be necessary in olive orchards characterised by different densities and architecture, as well as in other tree and woody crops, so as to improve the parameterisation and use of the METRIC algorithm.

The impact of climate change on irrigation water requirements of maize hybrids was investigated in the paper of Monaco et al. (2014). They evaluated functions for the yield response to water availability of 21 different maize hybrids for an irrigated district in Southern Italy, based on simulations using the agro-hydrological model SWAP (Kroes, Van Dam, Groenendijk, Hendriks, \& Jacobs, 2008) under reference (1961-1990) and future (2021-2050) climate and considering different irrigation levels, in order to determine the adaptive capacity of the hybrids to climate change. Considering the future climate scenario during the periods of maize cultivation, characterised by an increase of minimum and maximum temperatures and a decrease of precipitation with significant changes in temporal distribution, the results of simulations evidenced how the differences in the soil hydrologic behaviour, due to different soil physical properties, plays an important role in the evaluation of crop adaptability. In the future scenario in fact, two Soil Typological Units among those considered, could pose serious limitations of water availability for several maize hybrids.

Gandolfi et al. (2014), based on the use of an integrated approach combining hydrologic, economic and decision models, attempted to explore the effects of the European Common Agricultural Policy (CAP) on the process of water resources planning at the basin scale, as prescribed by the Water Framework Directive (WFD). The methodological approach was applied to the basin of Adda river, in Northern Italy, which covers $7000 \mathrm{~km}^{2}$ including the regulated Lake Como. The results showed how the CAP may lead to adjustments in the agricultural sector and particularly a shift towards more extensive land use and greater diversification of production. These changes can significantly reduce water requirements, by amounts that, in some areas among those investigated, could be greater than $10 \%$. As a consequence, the reduction of irrigation demand at basin scale can contribute to a higher degree of satisfaction for other water users as well as being able to meet the objectives of the WFD. 


\section{R E F E R E N C E S}

Cammalleri, C., Ciraolo, G., Minacapilli, M., \& Rallo, G. (2013). Evapotranspiration from an olive orchard using remote sensing-based dual crop coefficient approach. Water Resources Management, 27, 4877-4895.

De Jesus Souza, W., Rodrigues Sinobas, L., Sánchez, R., Arriel Botrel, T., \& Duarte Coelho, R. (2014). Prototype emitter for use in subsurface drip irrigation: manufacturing, hydraulic evaluation and experimental analyses. Biosystems Engineering, $128,41-51$.

Díaz, R., Rasheed, A., Peillón, M., Perdigones Perdigones, A., Sánchez, R., Tarquis, A. M., et al. (2014). Wind pumps for irrigating greenhouse crops: comparison in different socioeconomical frameworks. Biosystems Engineering, 128, 21-28.

Gandolfi, C., Sali, G., Facchi, A., Tediosi, A., Bulgheroni, C., Rienzner, M., et al. (2014). Integrated modelling for agricultural policies and water resources planning coordination. Biosystems Engineering, 128, 100-112.

Gumiere, S., Lafond, J. A., Hallema, D. W., Périard, Y., Caron, J., \& Gallichand, J. (2014). Mapping soil hydraulic conductivity and matric potential for water management of cranberry: characterization and spatial interpolation methods. Biosystems Engineering, 128, 29-40.

Jha, M. K., \& Chowdary, V. M. (2006). Challenges of using remote sensing and GIS in developing nations. Hydrogeology Journal, 15, 197-200.

Kroes, J. G., Van Dam, J. C., Groenendijk, P., Hendriks, R. F. A., \& Jacobs, C. M. J. (2008). SWAP version 3.2. Theory, description and user manual. Alterra Report 1649(02). Wageningen, Alterra, 262 page(s).

Levy, G. L., Fine, P., Goldstein, D., Azenkot, A., Zilberman, A., Chasan, A., et al. (2014). Long term irrigation with treated wastewater (TWW) and soil sodification. Biosystems Engineering, 128, 4-10.

Monaco, E., Bonfante, A., Alfieri, S. M., Basile, A., Menenti, M., \& De Lorenzi, F. (2014). Climate change, effective water use for irrigation and adaptability of maize: a case study in Southern Italy. Biosystems Engineering, 128, 82-99.

Pôças, I., Paço, T. A., Cunha, M., Andrade, J. A., Silvestre, J., Sousa, A., et al. (2014). Satellite based evapotranspiration of a super-intensive olive orchard: application of METRIC algorithm. Biosystems Engineering, 128, 69-81.

Rallo, G., Baiamonte, G., Manzano Juárez, J., \& Provenzano, G. (2014). Improvement of FAO-56 model to estimate transpiration fluxes of drought tolerant crops under soil water deficit: application for olive Groves. Journal of Irrigation and Drainage Engineering. http://dx.doi.org/10.1061/(ASCE)IR.19434774.0000693. A4014001.

Rallo, G., Minacapilli, M., Ciraolo, G., \& Provenzano, G. (2014). Detecting crop water status in mature olive groves using vegetation spectral measurements. Biosystems Engineering, 128, $52-68$.

Rallo, G., \& Provenzano, G. (2013). Modelling eco-physiological response of table olive trees (Olea europaea L.) to soil water deficit conditions. Agricultural Water Management, 120, 79-88.

Requejo Mariscal, M. I., Cartagena Causapé, M. C., Villena Gordo, R., Arce Martínez, A., Ribas Elcorobarrutia, F., Cabello Cabello, M. J., et al. (2014). Wine-distillery waste compost addition to a drip-irrigated horticultural crop of central Spain: risk assessment. Biosystems Engineering, 128, 11-20.

Santos, C., Lorite, I., Tasumi, M., Allen, R., \& Fereres, E. (2010). Performance assessment of an irrigation scheme using indicators determined with remote sensing techniques. Irrigation Science, 28(6), 461-477. 